REVISTA DE DERECHO UNED, NÚM. 8, 2011

\title{
MEMORIA HISTÓRICA DE LA JURISDICCIÓN VOLUNTARIA
}

\author{
ANTONIO FERnÁNDEZ DE BuJÁN \\ Catedrático de la Universidad Autónoma de Madrid. Vocal de la \\ ponencia de Reforma de la Jurisdicción Voluntaria. Comisión general \\ de codificación.
}

Resumen: Es hora ya de que la Jurisdicción Voluntaria deje de ser un campo de experimentación del legislador. Estamos ante la oportunidad de modernizar la Justicia en esta materia y de hacerlo con voluntad de permanencia en el tiempo, desde una posición de consenso y de progreso, en una esfera del Ordenamiento de marcado carácter técnico-jurídico.

Palabras clave: Jurisdicción voluntaria, autoridad jurisdiccional, secretario del tribunal, notario, registrador.

Abstract: It is time that Voluntary Jurisdiction ceases to be a mere area of experimentation for the legislator. We now have the opportunity to modernize Justice in this subject and to do so with the will of assuring its permanence in the future, from a position of consensus and progress and in a decidedly technical sphere of the Jurisdictional Order.

Keywords: Voluntary jurisdiction, jurisdictional authority, clerk of the court, notary, registry.

Sumario: I. Reforma legislativa pendiente.-II. El nuevo perfil de la institución: concepto, contenido y sanción constitucional.-III. Racionalizar. Desjudicializar. Redistribuir. Desregular.-IV Algunas vicisitudes de la Jurisdicción Voluntaria a partir de la retirada del Proyecto de Ley sobre la materia el 24 de octubre de 2007.- V A modo de conclusión. 


\section{REFORMA LEGISLATIVA PENDIENTE}

En el marco del Estado Constitucional de Derecho, una de las piezas que todavía queda por encajar en el organigrama de la Administración de Justicia es la correspondiente a la Jurisdicción voluntaria. La Ley de Enjuiciamiento Civil de 7 de enero del 2OOO, LEC, por la que se rige la jurisdicción contenciosa en los procesos civiles, establece en su Disposición Final decimoctava que: «En el plazo de un año, a contar de la fecha de entrada en vigor de esta Ley, el Gobierno remitirá a las Cortes Generales un proyecto de Ley sobre jurisdicción voluntaria». La reforma de la jurisdicción voluntaria fue asimismo prevista en el Pacto de Estado sobre la Justicia firmado por los dos partidos mayoritarios en España, el 28 de mayo del año 2001*.

Por otra parte, en la afortunada y precisa Exposición de Motivos de la LEC se afirma, en el apartado quinto, que en cuanto a su contenido general, dicha ley «se configura con exclusión de la materia relativa a la jurisdicción voluntaria que, como en otros países, parece preferible regular en ley distinta». Especial significación tiene en este campo la Ley de Jurisdicción Voluntaria alemana (Freiwllige Gerichtsbarkeit) de 1898 que, con más de treinta reformas parciales, continúa en vigor.

Un primer paso importante en el cumplimiento del mandato legislativo pendiente de cumplimiento, tuvo lugar en diciembre del año 2002, al ponerse en marcha la maquinaria legislativa con la constitución, en el seno de la Sección Segunda de la Comisión General de Codificación, máximo órgano asesor del Ministerio de Justicia en las tareas prelegislativas, de una Ponencia, presidida por D. José María de Prada y compuesta por siete miembros, que a lo largo de casi tres años de trabajo, elabora una propuesta normativa integrada por 306 artículos y 10 disposiciones complementarias -valoradas y tenidas muy en cuenta las observaciones formuladas por las Secciones de Derecho Civil y de Derecho Mercantil de la Comisión de Codificación -que asumida como Propuesta de Anteproyecto por el Ministerio de Justicia, es publicada en su Boletín Informativo en octubre del año 2005 «como texto preliminar de una nueva regulación de la jurisdicción voluntaria, sin duda necesaria, por lo que se hace pública por su evidente interés para la comunidad jurí-

* El presente artículo ha sido elaborado en el marco del Proyecto de Investigación, del que el Autor es el Investigador Principal: «La Jurisdicción Voluntaria: Un Proyecto Legislativo pendiente de cumplimiento». Ministerio de Ciencia e Innovación. DER2008-06460-C02-C1 
dica, al objeto de propiciar su conocimiento y libre discusión», según se subraya en la Nota que antecede a la Memoria Explicativa y a la Exposición de Motivos. La ponderada propuesta de Anteproyecto elaborada por la Comisión General de Codificación gozó, de forma manifiesta, de una positiva acogida en la comunidad científica y por parte de los operadores jurídicos afectados, Jueces, Secretarios Judiciales, Notarios, Registradores, Abogados y Procuradores de los Tribunales.

A partir de este primer paso relevante del prelegislador, la propuesta de Anteproyecto de la Ponencia fue sometida a una revisión interna en el Ministerio de Justicia, fruto de la cual fue el Anteproyecto de Ley de Jurisdicción Voluntaria, aprobado en Consejo de Ministros de 2 de junio de 2006. El veinte de octubre del año 2006, el Consejo de Ministros aprobó la remisión a las Cortes Generales del Proyecto de Ley de Jurisdicción Voluntaria, para facilitar y agilizar la tutela y garantía de los derechos de la persona, en materia civil y mercantil, que reprodujo, con escasas modificaciones, el texto del Anteproyecto de Ley de junio de 2006, y si bien introdujo mejoras en determinados aspectos contemplados en el Anteproyecto de la Ponencia, cambió la concepción de la JV, al administrativizar el procedimiento judicial en la terminología y en el contenido y establecer una artificiosa equiparación, entre procedimientos de diferente naturaleza, como son el judicial y el administrativo notarial y registral, lo que se materializó en la supresión de la contradicción, de los recursos y de la asistencia técnica en los procedimientos judiciales.

La desacertada, a mi juicio, previsión que implicaba un estéril reduccionismo de la JV al ámbito negocial y administrativo, fue por fortuna corregida en trámite de enmiendas en la Comisión de Justicia del Congreso de los Diputados, que procedió a la recuperación de las connotaciones jurisdiccionales del procedimiento judicial de JV, y a una distinta regulación de los procedimientos judicial y administrativo de JV, en atención a su diferente naturaleza jurídica, y a las reglas de funcionamiento y principios informadores propios de su conformación en el Ordenamiento Jurídico. En trámite de enmiendas se presentó un total de 323 al articulado del Proyecto.

El 27 de junio de 2007, fue aprobado en la Comisión de Justicia del Congreso de los Diputados, con Competencia Legislativa Plena, el Proyecto de Ley de Jurisdicción Voluntaria, antes denominado Proyecto de Ley de jurisdicción voluntaria para facilitar y agilizar la tutela y garantía de los derechos de la persona en materia civil y mercantil, con un contenido de 229 artículos y 17 disposiciones 
complementarias, el 24 de julio, el texto legislativo, entró en el Senado, en cuya Comisión de Justicia los distintos Grupos Parlamentarios presentaron y debatieron un total de 239 enmiendas. Finalmente, el 24 de octubre de 2007, día en el que iba a ser votado en el Pleno del Senado, el Gobierno procedió a retirar el Proyecto de Ley de Jurisdicción Voluntaria.

En tanto no se apruebe una Ley de Jurisdicción Voluntaria, continúa vigente, con determinadas excepciones, conforme se establece en la disposición derogatoria única, apartados 1 y 2 de la nueva LEC, la regulación contenida en el libro III de la LEC 1881, relativa a la Jurisdicción Voluntaria, así como la correspondiente a la conciliación y a la declaración de herederos abintestato. En contraposición, sin embargo, con la mencionada previsión legal, con la conciliación ha pasado lo que sucedió con las diligencias preliminares, que siendo ambas instituciones propias de la jurisdicción voluntaria han sido reguladas en sedes de naturaleza heterogénea. Así, la conciliación en la reciente Ley de Reforma de la legislación procesal para la implantación de la Nueva Oficina Judicial, y las diligencias preliminares en la Ley de Enjuiciamiento Civil, reguladora de la jurisdicción contenciosa $^{1}$.

Conviene señalar, por otra parte, que si bien un amplio número de los supuestos de jurisdicción voluntaria judicial se contienen en el libro III de la LEC, otros muchos en los que está prevista la intervención del juez o se incluyen en el marco de la denominada jurisdicción voluntaria notarial o registral, se regulan en textos legislativos diversos, como el Código Civil, el Código de Comercio, la Legislación hipotecaria, o la Ley y el Reglamento del Registro Civil.

En los últimos años, se ha generado, en un marco de expansión de la institución, una inflación de procedimientos específicos, sin que exista proceso, contemplados en leyes civiles o mercantiles, que no siempre resultan justificados en su especificidad, pero que en buena medida se amparan en la ausencia de un procedimiento global de jurisdicción voluntaria en el libro III de la LEC. Cabría citar, entre otros textos, en los que se regulan actos de jurisdicción volun-

${ }^{1}$ En este sentido en Díez-Picazo, I., Derecho Procesal Civil. El proceso de declaración, Madrid, 2001, pp. 229: «...aunque la doctrina considera las diligencias preliminares actuaciones de jurisdicción voluntaria, y la jurisdicción voluntaria ha quedado fuera del ámbito objetivo de la LEC, en este caso el legislador ha hecho una excepción a esa regla. Probablemente la razón de que la LEC, regule las diligencias preliminares pese a ser actos de jurisdicción voluntaria debe buscarse en la necesidad que había de introducir cambios en su regulación para darles mayor eficacia, lo que no debía esperar hasta la aprobación de la futura Ley de Jurisdicción Voluntaria». 
taria, las siguientes disposiciones legislativas: ley 30/1979, de 27 de diciembre, en materia de trasplantes de órganos; Ley 50/1980, de 8 de octubre, sobre Contrato de seguro, a propósito de nombramiento de tercer perito; ley 11/1981, de 13 de mayo, en materia de filiación, patria potestad y régimen económico del matrimonio; Ley 30/1981, de 7 de julio, sobre nulidad, separación y divorcio; Ley 1/1982, de 5 de mayo sobre derecho al honor, intimidad personal y familiar y propia imagen, en relación con los menores; ley 13/1983, de 24 de octubre, sobre tutela y curatela; Ley 19/1985, de 16 de julio, Cambiaria y del Cheque; Ley Foral de Navarra 5/1987, de 1 de abril, sobre autorización judicial para enajenar o gravar bienes fideicomisarios; Ley 21/1987, de 11 de noviembre, en materia de acogimiento y adopción; Ley 22/1987, de 11 de noviembre, en materia de Propiedad Intelectual, en supuestos de discrepancias sobre remuneración equitativa del autor, divulgación de la obra, subsanación de omisiones, reanudación de explotación de obra etc., que requieran autorización judicial; Ley de la Generalitat de Cataluña, 40/1991, de 30 de diciembre, reguladora del Código de Sucesiones por causa de muerte, sobre autorización judicial en materia de conmutación o conversión del modo que grava una institución de heredero o de legado; Ley 1/1996, de 15 de enero, de Protección Jurídica del menor; Ley de la Generalitat de Cataluña 9/1998, de 15 de julio, reguladora del Código de Familia, en materia de idoneidad para la adopción; Ley de la Generalitat de Cataluña, 18/2002, de 5 de julio, en materia de cooperativas, Ley 9/2000, de 10 de diciembre, sobre sustracción de menores; Ley 41/2003, de 18 de noviembre, sobre Protección patrimonial de las personas con discapacidad, etc.

\section{EL NUEVO PERFIL DE LA INSTITUCIÓN: CONCEPTO, CONTENIDO Y SANCIÓN CONSTITUCIONAL}

La Jurisdicción Voluntaria, JV en adelante, ha sido descrita o calificada por la doctrina y la jurisprudencia con los más variados epítetos: misteriosa, heterogénea, fascinante, atormentada, insistente, machacona y dando respuesta a problemas concretos, repudiada por todos y sin sede científica propia, enojosa, difícil y de poco lucimiento, uno de los más atormentados problemas de la ciencia jurídica europea, la gran olvidada y por qué no decirlo, la gran ignorada, autoritaria, inquisitiva y paradigmática por su brevedad y economía procesal pero, en la práctica, salvo valiosas excepciones, ha suscitado escaso interés en la doctrina científica y en el desarrollo argumental de la doctrina jurisprudencial, si nos atenemos a la relevancia de la 
parcela imprescindible de la realidad social que constituye su campo de aplicación ${ }^{2}$.

Frente a posiciones maximalistas del tipo «la jurisdicción voluntaria podría ser eliminada de cualquier Ordenamiento Jurídico» o la de «las necesidades negociales y el tráfico jurídico, justifican la aplicación del procedimiento voluntario a supuestos de lesión de derechos o intereses legítimos», se impone una posición realista, en la que sitúan las más modernas corrientes de la ciencia procesal, partidarias de regular, sin quiebra de las garantías esenciales del proceso, y sin desnaturalizar el marco que le es propio, una parcela imprescindible de la realidad social, en constante expansión, fruto del nuevo perfil de la jurisdicción voluntaria, que ha evolucionado desde la originaria tutela de relaciones jurídico privadas, a la actual protección de derechos indisponibles, intereses generales, públicos o sociales, así como a la resolución de conflictos de intereses considerados de relevancia menor.

No debería, finalmente, extenderse artificiosamente el campo de la jurisdicción voluntaria fuera de su propio ámbito, por meras ra-

${ }^{2}$ En análogo sentido, se manifiesta MuÑoz RoJAs, Sobre la jurisdicción voluntaria, Actualidad Civil, 1989, num. 39/90, pp. 577-585, cuando afirma que : «en el ámbito jurídico, es tan necesaria la jurisdicción voluntaria como la jurisdicción contenciosa: cada una de ellas tiene su respectivo campo de aplicación y no son intercambiables. Si está justificada en nuestro Ordenamiento la reforma de las leyes procesales, la misma o mayor justificación tiene la depuración, actualización o mejora de los expedientes de jurisdicción voluntaria adaptados a la reforma de las leyes sustantivas, sin perjuicio de la ley básica de dichos procedimientos». Especial relevancia en la doctrina española en la materia tienen las obras de Ramos Méndez, La jurisdicción Voluntaria en Negocios de Comercio, Madrid 1978; Almagro, en Derecho Procesal Civil, T. I, Vol. II, Valencia 1992; y Gónzalez Poveda, La Jurisdicción Voluntaria, Pamplona, $3^{\text {a }}$ ed. 1997.

En el último decenio, la previsión legislativa referida a la jurisdicción voluntaria ha estimulado la producción doctrinal. Vid. al respecto, entre otros estudios, en Fernández de Buján, A., Jurisdicción voluntaria. Madrid, 2001; Id. Hacia una Teoría General de La Jurisdicción Voluntaria I, Iustel, Madrid 2007; Id. Hacia una Teoría General de la Jurisdicción Voluntaria II, Iustel, Madrid 2008; Id. La Oficina Judicial y la Jurisdicción Voluntaria: dos reformas procesales a debate en el panorama legislativo español, Estudios en Homenaje al Profesor Elías Díaz, RJUAM, Revista Jurídica de la UAM, 2009, y en: Publicaciones de la Real Academia de Jurisprudencia y Legislación: Problemas actuales de la Jurisdicción, T.II, pp. 1462-1477. Fecha: 2010; Id. El necesario debate sobre el nuevo modelo de Oficina Judicial, Número especial de La Ley sobre la Oficina Judicial. N. 7.191, de 8 de junio de 2009, pp. 8-11; De Prada González, En torno a la futura ley de jurisdicción voluntaria, en El Notario del Siglo XXI, diciembre 2005; Rodriguez Adrados, El anteproyecto de ley de jurisdicción voluntaria, Anales de la Real Academia de Jurisprudencia y Legislación, Madrid 2006; Seoane Cacharrón, Breve examen crítico del Anteproyecto de Ley de Jurisdicción Voluntaria del Ministerio de Justicia de 1 de junio de 2006, La Ley, 28-9-2006. 
zones de economía procesal, lo que se produciría si se tramitasen por la vía del procedimiento voluntario supuestos de tutela de derechos o intereses lesionados o supuestos de conflicto relevante. No se puede establecer una jurisdicción voluntaria contra natura por un simple deseo de celeridad. Una cosa es que se facilite la transacción, y el compromiso, y otra es que se desnaturalice en un procedimiento voluntario, el conocimiento de supuestos en los que lo que subyace es la tradicional lucha por el derecho.

Sería deseable, en todo caso que, se valorase la creación, en el futuro, de juzgados que tuviesen atribuida la competencia en exclusiva en esta materia, tal como sucedía en la Edad Media, con los iudices chartularii, ante los que, en atención a su especialización judicial, se desarrollaba, con carácter exclusivo, la ficción procesal que encubría el negocio de jurisdicción voluntaria. En los pasados decenios en torno a un $10 \%$ de los asuntos conocidos en los juzgados civiles se corresponden con procedimientos de jurisdicción voluntaria.

No es la jurisdicción voluntaria una simple expresión nominal que, utilizada por el legislador como campo de experimentación o mero catalizador de procedimientos heterogéneos, carezca de justificación racional, ni de fundamentación histórica. Muy por el contrario, ya en Derecho Romano, existió el sustrato social y la realidad jurídica, de lo que por primera vez, en la historia de la ciencia jurídica europea, un jurista romano, del siglo III d.C., llamado Marciano, en su obra Instituciones, con posterioridad recogida en el Digesto de Justiniano, denomina jurisdicción voluntaria, «iurisdictio voluntaria». Asimiladas en la época clásica romana a la jurisdicción voluntaria determinadas actuaciones formalizadas ante los funcionarios encargados de los Archivos o Registros Públicos y ante los Notarios o Tabeliones, es en la Edad Media cuando se atribuye ya a los Notarios competencias específicas en materia de jurisdicción voluntaria, primero como profesionales adscritos a los tribunales y con posterioridad como titulares de los juzgados, iudices chartularii, con competencia específica para conocer de los asuntos de jurisdicción voluntaria, ante los que se desarrollaba la ficción procesal que encubría el negocio de jurisdicción voluntaria, en una primera etapa, superada la cual se procedía a la formalización del procedimiento de jurisdicción voluntaria, tramitado fuera ya del marco del proceso contencioso.

La expresión JV se trasmite en la Edad Media, a través de los glosadores y comentaristas al Derecho Común, y de éste pasa a los códigos modernos y a las legislaciones de los distintos países europeos 
La denominación de Jurisdicción Voluntaria tiene por tanto una fundamentación histórica derivada de su utilización sin intervalos durante casi veinte siglos, y la reforma de la Justicia no debe ni puede prescindir de la historia, en afortunada expresión de la EM de la LEC , a lo que ha de añadirse el valor derivado del arraigo de una terminología utilizada de forma usual en el lenguaje común, en el de los operadores jurídicos y en la tradición jurisprudencial, así como la inutilidad de los esfuerzos doctrinales y legales realizados en otras latitudes para encontrar una expresión comprensiva del fenómeno que nos ocupa.

Así, denominaciones como proceso no contencioso o procedimiento en Cámara de Consejo se han revelado como insatisfactorias, y no han logrado sustituir en los propios países en que se han introducido a la denominación clásica que ha seguido presente en las aportaciones científicas y, en ocasiones, de forma casi freudiana, en el propio texto de la ley ${ }^{3}$. Jurisdicción contenciosa y voluntaria, una vez desgajadas de ésta las artificiosas adherencias que no le son propias, constituyen esferas de la jurisdicción, que requieren una actividad de enjuiciamiento del órgano jurisdiccional, si bien en la jurisdicción voluntaria que se enmarca, en gran parte de su contenido, en el amplio campo del ejercicio pacífico de los derechos, y de ahí la justificación funcional de la denominación, no existen, en general, posiciones contrapuestas, a priori, de personas enfrentadas, salvo supuestos de conflictos de relevancia menor, mientras que en la jurisdicción contenciosa, lo normal es la existencia de una controversia entre los litigantes, aunque hay también procesos declarativos o constitutivos en los que no existe oposición. Se trata de auténticos procesos sin contradicción de voluntades, como por ejemplo sucede en los supuestos de las denominadas sentencias sin oposición

\footnotetext{
${ }^{3}$ Art. 32, disp. Att. del Código Civil Italiano: «el ministerio público debe ser oído siempre en los procedimientos de jurisdicción voluntaria que tienen contenido patrimonial»; arts. 35 y 36 del D.P.R., 5 de enero de 1967, n. 200, que regulan las funciones y competencias de los cónsules en materia de jurisdicción voluntaria; arts. 9, 66 y 67 de la reciente ley de 31 de mayo de 1995, reformadora del sistema italiano de derecho internacional privado, mediante los que se regulan las hipótesis en que subsiste la jurisdicción del juez italiano en materia de jurisdicción voluntaria, así como los presupuestos y la eficacia en Italia de los procedimientos de jurisdicción voluntaria en los que intervienen jueces extranjeros. Vid. al respecto en Venturini, Consideración sulla qualificazione dei procedimenti stranieri di giuridiszioni volontaria, Rivista di Diritto Internazionale privato e procésale, 2003, pp. 813-910. En relación con el estudio histórico de la institución de la jurisdicción voluntaria vid., FERNÁNDEZ DE BuJAN, A., Jurisdicción voluntaria en Derecho Romano, Madrid, $3^{\mathrm{a}}$ ed. 1999.
} 
Con la expresión jurisdicción voluntaria, en sentido estricto, se hace referencia a aquellos procedimientos en los que un particular solicita la intervención de un juez, o éste interviene de oficio o a instancia del Ministerio Fiscal sin que exista una contienda relevante con otra persona, o una lesión de derecho subjetivo o interés legítimo.

Son, por ejemplo, supuestos de jurisdicción voluntaria -de entre los más de 200 pendientes de nueva regulación, racionalización y redistribución- la adopción de medidas relativas al traslado o retención ilícita de menores en actuaciones de sustracción internacional; la aprobación del reconocimiento de la filiación extramatrimonial; la protección patrimonial de las personas con discapacidad; la declaración de ausencia o fallecimiento de una persona; que se proceda al nombramiento de un tutor o que se autorice a éste la venta de un inmueble de su pupilo; la constitución de una adopción o de un acogimiento familiar; las autorizaciones relacionadas con el honor, la intimidad o la propia imagen del menor; la autorización para el trasplante de órganos de personas fallecidas; que se autorice la convocatoria de una junta general ordinaria de sociedad anónima que no se hubiese convocado en el plazo legal; que se acuerden medidas de garantía en relación con la mala administración de los padres; que se disponga el depósito y venta de mercancías y equipajes en los casos en que el destinatario no abone el flete o el pasaje; la auditoría de las cuentas de los empresarios; el nombramiento de perito en el seguro de daños; que se autorice al capitán del buque, la venta de un cargamento, en peligro de avería, en el puerto de arribada y no en el de destino; la liquidación y distribución de una avería gruesa, en materia de derecho marítimo, o los supuestos de intervención judicial, sin que exista proceso, en relación con la restricción de derechos fundamentales.

Se incluyen asimismo dentro de la esfera de la jurisdicción voluntaria un conjunto de procedimientos dirigidos a la solución judicial de conflictos que el ordenamiento jurídico considera que no tienen entidad suficiente para ser dirimidos en un proceso contencioso, entre los que cabe señalar las controversias entre los progenitores en el ejercicio de la patria potestad, o los desacuerdos entre los esposos en la gestión de los bienes comunes. Se trataría de supuestos en los que la urgencia o la conveniencia de eludir la excesiva dilación del juicio ordinario, justificaría la tutela simplificada, ágil y flexible del procedimiento voluntario, que cumpliría, en estos casos, el papel que correspondería a un especial procedimiento sumario contradictorio.

Son considerados finalmente procedimientos de jurisdicción voluntaria judicial otros supuestos en los que la intervención del juez queda reducida a la mera presencia, comprobación de hechos, califi- 
cación, autentificación o documentación del acto o relación jurídica, lo que supone una desnaturalización de lo que debe entenderse por potestad jurisdiccional, ni parece asimismo necesaria en éstos supuestos la actuación judicial en garantía de derechos, que con carácter compartido con otros poderes del Estado, se atribuye a los jueces y tribunales en el artículo 117.4 de la Constitución.

Sería pues deseable, en este ámbito de reflexión, y en atención a las enseñanzas de la experiencia histórica, la dogmática jurídica y la realidad social propia de esta esfera del Ordenamiento, deslindar entre aquellas competencias que deben continuar atribuidas al órgano jurisdiccional, por razón de su naturaleza jurídica, o bien debido a la consideración de los jueces como los operadores jurídicos que gozan de un mayor grado de independencia e imparcialidad en el ejercicio de su función, y aquellas otras competencias que, atribuidas en su momento -finales del siglo XIX-a los jueces, en atención a su prestigio, a la seguridad jurídica que producía su intervención, a la prevención o desconfianza frente a otros operadores jurídicos, o a razones de mera tradición historicista, oportunidad, conveniencia o división del trabajo, podrían desjudicializarse, al desparecer las razones de política legislativa que constituían su fundamento, y atribuirse, en la parte correspondiente a disposiciones finales, a profesionales del derecho, Notarios y Registradores de la Propiedad y Mercantiles, a quienes corresponden con mayor propiedad el ejercicio de estas funciones, en atención a su propia naturaleza así como a su especialización y cualificación jurídicas. Se trataría con ello no tanto de evitar el colapso de la justicia contenciosa, sino sobre todo de sistematizar y redistribuir funciones, en aras de la racionalización del sistema y como demostración de confianza en la madurez de la sociedad civil.

La intervención de oficio del juez y del fiscal está prevista en supuestos de procedimientos de jurisdicción voluntaria que afectan a menores, incapacitados o desvalidos, en estrecha relación con los preceptos constitucionales (arts. 9.2 y 53.3 CE) referidos al Estado social, o bien a la condición y estado civil de las personas, o a intereses jurídico-públicos, generales o sociales.

La nueva concepción de la JV judicial debe caracterizarse por su sustancial aproximación a la jurisdicción contenciosa, en materia de garantías del procedimiento. La previsión legal contenida en el artículo del Proyecto de Ley del Gobierno conforme a la cual: «La comparecencia se sustanciará por los trámites del juicio verbal con las siguientes especialidades», supone la supresión de las particularidades previstas en materia de JV y una práctica equiparación en la regulación de ambas esferas de la jurisdicción. Así en materias como: 
- Días y horas hábiles;

- Desaparición de la posibilidad de modificar de oficio las providencias y autos no definitivos, conforme al 1818 LEC, que suponía una desvirtuación de lo previsto en la LOPJ, arts. 18 y 267, que establecen el principio de que las resoluciones judiciales sólo quedarán sin efecto en virtud, en su caso, de los recursos previstos por las leyes;

- Reforzamiento del principio de igualdad de partes, en la medida en que se produce una atenuación o práctica desaparición, en algunos casos de JV, de la posición de solicitantes, interesados (es decir, personas con interés concurrente o complementario, de cualquier tipo, jurídico, económico, moral etc., con el del solicitante), contrainteresados (es decir, personas con interés divergente al expresado por el solicitante) y afectados, en relación con la audiencia, alegaciones, testimonios(por ej. de terceros no interesados a las que el procedimiento no afecta, en sentido estricto, a sus intereses),pruebas (en contraposición a las actuales informaciones, acreditaciones y justificaciones), trámite de conclusiones, registro de la comparecencia en soporte apto para la reproducción del sonido y la imagen, plazo para subsanar los posibles defectos u omisiones en las solicitudes, asistencia técnica, justicia gratuita, recursos etc., así como en aquellos supuestos en que por análogas motivaciones, rige el principio de impulso de oficio en el proceso contencioso o en el procedimiento de JV.

- Previsión de la controversia y la oposición

- Plazos cortos y prorrogables. Asunción, con carácter general, del principio preclusivo.

- Previsión se subsanación de posibles defectos u omisiones en las solicitudes, conforme al art. 23.1.

- Supresión del régimen singular de la apelación en uno o dos efectos, ex arts. 1819 y 1820.

- Previsión de supletoriedad de la Ley Procesal Civil, conforme al art. 12: «La Ley de Enjuiciamiento Civil será de aplicación supletoria a los expedientes de Jurisdicción Voluntaria administrados por Jueces y Secretarios Judiciales en lo no previsto por esta Ley».

Resultaría apropiado, asimismo, un reforzamiento de los principios dispositivo y de aportación de parte en el procedimiento volun- 
tario, una atenuación del dirigismo judicial, que en consonancia con la libertad de forma y el carácter más potestativo de la actuación judicial en esta esfera de la jurisdicción, pueda poner en riesgo las fundamentales garantías inherentes a todo procedimiento, una limitación del principio de impulso de oficio a aquellos supuestos de derechos indisponibles o de interés general, públicos o sociales y una aproximación de las posiciones de solicitante, interesados y terceros, en especial en aquellos supuestos en los que el interesado exprese un interés contrario al manifestado por el promovente, es decir, en aquellos casos en que nos encontremos en presencia de lo que se denomina contrainteresado en la legislación italiana, no obstante lo cual, no se produce un sobreseimiento del expediente.

El carácter variable y fluido entre jurisdicción contenciosa y jurisdicción voluntaria, en atención a las decisiones contingentes de política legislativa ha sido por otra parte, una constante en la historia de ambas esferas de la jurisdicción, y así por ejemplo los alimentos provisionales y la incapacitación por locura, fueron en una primera época de vigencia de la LEC 1881 expedientes de jurisdicción voluntaria, siendo con posterioridad transvasados a la jurisdicción contenciosa. En la misma línea, el legislador de la Ley Procesal Civil del año 2000 ha incluido en su seno supuestos que con anterioridad se regulaban por el trámite voluntario, como el internamiento de personas incapaces por trastornos psíquicos o conforme al artículo 770 LEC, las pretensiones que se formulan al amparo del título IV, libro I del Código Civil, relativo al matrimonio, que se sustanciarán por los trámites del juicio verbal.

A la necesidad de regular la contradicción en el procedimiento de JV judicial, que constituía, a mi juicio, la deficiencia de mayor calado del texto legislativo presentado por el Gobierno, se refirieron todos los expertos que comparecieron en la Comisión de Justicia del Congreso de los Diputados, entre ellos el autor del presente estudio, los días 7 y 14 de mayo de 2007, a fin de asesorar sobre el contenido del Proyecto. Carece de sentido articular un procedimiento judicial garantista, como en efecto así se había hecho, en contraposición a la vigente previsión legal que adolecía de esta nota caracterizadora, entre otros aspectos, en materia probatoria y de audiencia, y aplicarlo tan sólo a menores e incapaces, como se preveía en el Proyecto del Gobierno. Resultaba asimismo artificioso optar por una concepción de la JV basada en la ausencia de conflictividad como elemento diferenciador con la jurisdicción contenciosa, conforme a un modelo ya superado en la vigente legislación sustantiva y procedimental, española y comunitaria, como así fue subrayado en los preceptivos dictámenes del Consejo General del Poder Judicial y del Consejo Fiscal. 
Lógicamente si se acude al órgano judicial, en numerosos supuestos de JV en los que no están afectados intereses de menores o incapacitados, es ante la falta de acuerdo entre los interesados. Así, por ejemplo, para proceder a la consignación de un objeto o de una cantidad de dinero; para fijar el plazo para el cumplimiento de una obligación; para obligar a exhibir la contabilidad de una empresa o a auditar las cuentas de un empresario; para convocar una junta o asamblea general; para nombrar un tercer perito en un contrato de seguro; para proceder a liquidar una avería gruesa, o para resolver las discrepancias surgidas en el contrato de fletamento, entre fletador, como titular de las mercancías transportadas y fletante, como porteador de éstas, por señalar sólo alguno de los muchos supuestos en los que la discordancia es manifiesta o está subyacente, es porque existe un problema sin resolver o una necesidad que atender del ciudadano que acude en ayuda del órgano judicial. En otras ocasiones, es el propio texto legal el que prevé que la oposición no hará contencioso el expediente, como así sucede en la presentación y adveración del testamento ológrafo o del testamento cerrado, o en los supuestos de extravío, sustracción o destrucción del conocimiento de embarque.

En materia de efectos de la controversia se volvió, en el curso de la tramitación parlamentaria, a la regulación prevista en el Anteproyecto de la Comisión de Codificación, lo que supone optar por hacer una Ley eficaz y que resuelva los problemas que se plantean cuando se acude a un operador jurídico para que incoe un procedimiento, dado que la opción por el archivo del expediente cuando se genere una controversia y la oposición consiguiente, traería consigo la ineficacia de la Ley y, en consecuencia, los ciudadanos dejarían de acudir a la JV. La razonable regulación de la oposición prevista en la Ponencia de la CGDC y asumida en el Congreso de los Diputados se contiene en el art. 7 conforme al cual: «Salvo que la ley expresamente lo prevea, la formulación de oposición por algún interesado en el asunto no hará contencioso el expediente ni impedirá la tramitación del mismo hasta su resolución, que surtirá los efectos que correspondan a tenor de su contenido en tanto no sea revocado o modificado en proceso declarativo promovido por persona legitimada». La fundamental enmienda sobre los efectos de la controversia, la n. 100, sin duda la esencial, a mi juicio, en el logro de una Ley de JV eficaz, fue presentada y defendida en la Comisión de Justicia del Congreso de los Diputados por el Grupo Parlamentario Mixto.

En relación con la sanción constitucional de la JV me parece plenamente acertado el análisis razonamiento contenido en el Fundamento de Derecho sexto de la STS de 22 de mayo del año 2000 ( Sala 
de lo Contencioso- Administrativo, Sección $6^{\mathrm{a}}$ ), de la que fue Ponente el Magistrado Peces Morate : «...El que se admita la existencia de actuaciones de jurisdicción voluntaria, atribuidas a órganos no judiciales, para los que tal denominación es harto discutible, no supone que cuando un juez o tribunal está llamado por Ley a definir un derecho o a velar por él, sin que exista contienda entre partes conocidas o determinadas( artículo 1811 de la vigente Ley de Enjuiciamiento Civil) su actuación no debe estar revestida de las garantías propias de la jurisdicción. No se puede afirmar que en la denominada jurisdicción voluntaria los jueces y tribunales no están ejerciendo funciones jurisdiccionales (juzgar y hacer ejecutar lo juzgado), con independencia de que ulteriormente quepa sobre lo mismo otro proceso contradictorio y, en consecuencia, esas potestades quedan amparadas por el artículo 117,3 de la Constitución, según el cual su ejercicio ha de hacerse con arreglo a las normas de competencia y procedimiento que las leyes establezcan. Las demás funciones, que el art. 117.4 CE permite que una Ley atribuya a los jueces y tribunales en garantía de cualquier derecho, son aquéllas que, a diferencia de las denominadas de jurisdicción voluntaria, no comportan protección jurisdiccional de derechos e intereses legítimos, como en los supuestos (citados por los demandados) de participación de jueces o magistrados en los Jurados de Expropiación Forzosa o en la Administración Electoral, en que aquellos se incorporan a otras Administraciones del Estado por la garantía que su presencia en ellas confiere...».

Si analizamos la actuación del Presidente del TSJ en la tramitación y resolución de dicho recurso, se constata la existencia de los requisitos o notas propias del ejercicio jurisdiccional, apareciendo incluso una que, de ordinario, no concurre en otras actuaciones de jurisdicción voluntaria en que intervienen los jueces y magistrados, cual es la contradicción.» ${ }^{4}$.

${ }^{4}$ Vid. especialmente en Ramos Méndez, Derecho Procesal Civil, T. III, cit., pp 1289 ss; Id. Jurisdicción Voluntaria en negocios de comercio, cit., pp. 23 ss.

Para TARZIA debe considerarse superado el antiguo aforismo iurisdictio in sola notione contentiosa consistit, y es necesario reivindicar algunas garantías fundamentales de la jurisdicción contenciosa también para la jurisdicción voluntaria, así por ejemplo las garantías de la independencia y la tercereidad del juez; para MonTESANO los derechos subjetivos e intereses tutelados por la jurisdicción tienen la misma naturaleza que los derechos subjetivos lesionados propios de la jurisdicción contenciosa, y especialmente en los casos de tutela de los derechos de los menores e incapacitados, el procedimiento seguido debe cumplir todas las garantías que informan los procesos contenciosos; Para DENTI, no cabe individualizar una jurisdicción voluntaria con características autónomas respecto de la jurisdicción en general, sino que, por el contrario, en cuanto que se atribuye a órganos judiciales, no se sustrae a las garantías 
Reparar lesiones de derechos o intereses legítimos o su no reconocimiento y dirimir controversias relevantes, constituye el núcleo esencial de la potestad jurisdiccional, y otorgar tutela judicial efectiva fuera del marco proceso contencioso, en conflictos cuya entidad no requiere un juicio ordinario o en defensa de derechos o intereses legítimos de menores, incapaces, personas con discapacidad, derechos indisponibles o intereses generales, públicos o sociales, mediante una actividad de enjuiciamiento y en aplicación del derecho objetivo, con todos los principios y garantías procesales, forma parte asimismo, a mi juicio, del contenido de facultades atribuidas con carácter exclusivo a Juzgados y Tribunales por el art. 117.3 CE o, en determinados supuestos, en garantía de derechos por el artículo 117.4 CE . En todo caso, la JV judicial, se configura como parte integrante de la idea de Administración de Justicia, considerada como función con un contenido más amplio que el propio del ejercicio de la potestad jurisdiccional.

Hay determinados procedimientos que, a mi juicio, necesariamente deben permanecer en el ámbito de la reserva jurisdiccional, y ello, únicamente lo garantiza el 117.3. Así no parece razonable trasvasar, con el actual marco constitucional, a una titularidad distinta de la judicial, procedimientos relativos a la autorización judicial para esterilizar un incapaz, o para el tratamiento no voluntario de una persona con trastornos psíquicos o para una intromisión legítima en el honor, en la intimidad o en la propia imagen de un menor o incapacitado o para autorizar o aprobar el reconocimiento de la filiación no matrimonial de menores o incapaces o para el nombramiento o remoción de un tutor o curador o para autorizar la venta de un bien del patrimonio de una persona con discapacidad o para decidir sobre la custodia de los menores cuando los padres vivan separados o sobre la atribución a uno sólo de los cónyuges de la facultad para realizar actos de administración o disposición de los bienes comunes. No parece, a mi juicio, razonable que en los señalados y en otros análogos supuestos de JV, quepa cuestionar que el Juez está realizando una actividad de enjuiciamiento propia de la potestad jurisdiccional, consistente en constituir, autorizar, habilitar o complementar la capacidad de una persona, tutelar un interés público o resolver un conflicto cuya relevancia no requiere, a juicio del legislador, que sea dirimido en un proceso contencioso, mediante un procedimiento contradicto-

subjetivas y objetivas, que caracterizan la actividad judicial. Las opiniones de estos autores se encuentran reflejadas en las Atti del XVII Convengo Nazionale del Processo civile en Palermo, celebrado en 1989. 
rio o de ejercicio pacífico del derecho, sustanciado con todas las garantías de la tutela judicial efectiva.

De modo que el legislador debe ser consciente que no parece acertado mantener que la fundamentación de la JV se asienta tan sólo en el párrafo 4 del art. $117 \mathrm{CE}$, dado que ello supondría que en el futuro pudiese decidirse que alguno o todos los supuestos mencionados se atribuyesen a otros operadores jurídicos, que no podrían ser, por razones obvias, otros profesionales distintos a los Secretarios Judiciales, Notarios o Registradores. Parece pues razonable o bien incardinar los procedimientos de Jurisdicción Voluntaria atribuidos a los Jueces en los apartados 3 y 4 del artículo 117 de la CE, o bien obviar esta cuestión en la futura Ley de Jurisdicción Voluntaria.

En el sentido expresado, se ha pronunció, en su preceptivo Dictamen al Proyecto de Ley, el Consejo General del Poder Judicial: pag. 23: «sin la nota de la exclusividad del apartado 3 del art. 117, el problema queda reducido a una mera opción del legislador, que podrá sustraer a la intervención judicial lo que constituyen manifestaciones de carácter constitutivo negocial, autorizaciones, aprobaciones u homologaciones.....».

\section{RACIONALIZAR, DESREGULAR, REDISTRIBUIR Y DESJUDICIALIZAR}

El marco constitucional en el que se desenvuelve la tutela judicial, no supone, por otra parte ningún obstáculo en esta materia, para racionalizar el sistema, desregular los procedimientos obsoletos, de nula aplicación práctica o de escasa eficacia, manifestaciones de la actual discordancia entre lo legislado y la actual realidad social, redistribuir entre jueces y secretarios las competencias asignadas al órgano jurisdiccional y desjudicializar aquellos supuestos que por su propia naturaleza jurídica, comprenden a otros profesionales del derecho, en especial notarios y registradores de la propiedad y mercantiles, en atención a su especialización y a la competencia funcional que se les reconoce por el Ordenamiento Jurídico.

La necesidad de descargar de trabajo a los jueces, concentrar su actuación en tareas jurisdiccionales, redistribuir competencias y racionalizar el sistema en la Administración de Justicia, constituyó, por otra parte, el objeto de una Recomendación del Consejo de Europa, dirigida a los países miembros de fecha 16 de septiembre de 1986. La desjudicialización supondrá la reforma de la correspondiente legislación notarial, registral, funcionarial o la de otros agentes 
jurídicos, respecto de los que se produzca el traspaso de competencias, dado que parece procedente que en la futura Ley de Jurisdicción Voluntaria se regulen tan sólo las competencias que se mantienen en la órbita judicial.

En la modificación de la Ley Orgánica del Poder Judicial, por Ley de 23-12-2003, artículos 438,3 y 5 y 456,3 y 4, se prevé, por su parte, la competencia de los Secretarios Judiciales, en los actos de jurisdicción voluntaria cuyo conocimiento se les atribuya en las futuras leyes procesales, lo que supone asimismo un reconocimiento expreso de la competencia de estos profesionales del derecho en este ámbito, en la línea con lo previsto en el art. 290 de la LOPJ de 1985, que ya les atribuía las propuestas de autos definitivos en materia de jurisdicción voluntaria.

Se descargaría con ello de competencias a los jueces, que se atribuirían a estos funcionarios del derecho, que integran el órgano jurisdiccional, al menos a partir de la LOPJ de 1985, conforme a la opinión de una parte de la doctrina procesalística, cualificados por su preparación jurídica y por su dominio de la técnica procesal, que se encuentran en el momento actual, al decir de la mayoría de los estudiosos que se han pronunciado sobre la cuestión, infrautilizados en el marco de la Administración de Justicia, no obstante, la relevancia de las funciones que se les atribuyen en el marco de la Administración de Justicia: dación de fe, dación de cuenta, ordenación procesal y determinadas competencias en el ámbito de la ejecución.

El procedimiento podría consistir en reconocerles competencia para dictar decretos motivados, con hechos, fundamentos de derecho y fallo, en los asuntos que se les atribuyan, decretos motivados que serían recurribles ante el Juez en primera instancia. La utilización del término decreto supondría, por otra parte, la recuperación de la denominación de la resolución «decretum», con la que el magistrado romano concluía el procedimiento de jurisdicción voluntaria, así como la armonización con la terminología utilizada en la legislación alemana -el Rechtsfleger alemán, equiparable al Secretario Judicial español, concluye el procedimiento de jurisdicción voluntaria, mediante un decreto motivado-, y en la legislación italiana. En los asuntos de jurisdicción voluntaria cuyo conocimiento se mantenga en la exclusiva competencia de los jueces, podría atribuirse al secretario, la tramitación del expediente que debería en todo caso se estudiado y decidido por el juez en auto motivado.

Notarios y Registradores son al propio tiempo, profesionales privados del derecho y órganos de la Administración pública, titulares activos de las funciones públicas que les atribuye el Ordenamiento 
Jurídico, y responsables de las actuaciones desarrolladas en su ejercicio ante los órganos judiciales.

En relación con la atribución de competencias que, podrían ser transferidas al Notariado ${ }^{5}$, cabe señalar que se hace imprescindible un amplio reconocimiento y atribución al Notariado de competencias desjudicializadas en este sector del Ordenamiento, en atención a la doble condición de los Notarios, de titulares de una función pública al servicio de los intereses generales, y de profesionales privados del derecho, lo que supondrá, por otra parte, la recuperación de un protagonismo en un ámbito, que ya les había sido reconocido por la historia, en atención al desempeño de funciones de autenticación, notificación, documentación, acreditación y ciertos supuestos de homologación y de fe pública extrajudicial, mera presencia o comprobación de hechos y garantía de derechos, en consonancia con la seguridad jurídica preventiva y la finalidad antilitigiosa de la actividad notarial, y que han hecho que el Notario actual, en palabras de Rodríguez Adrados, «no sea un mero fedatario público, sino que realiza un juicio de legalidad del acto en que interviene, cuidando que no sea contrario a las leyes ordinarias y a los presupuestos constitucionales, al propio tiempo que debe realizar un juicio de asesoramiento de los intervinientes».

La función notarial se ejerce, por otra parte, de forma independiente e imparcial, sin sometimiento a ordenación jerárquica, y su actuación, incluso en su función de dar fe pública, está sometida al control judicial. No constituye la actividad notarial un servicio público en su concepción administrativa, aunque si supone el ejercicio de un servicio público en cuanto a su función certificante y autorizante, en la medida en que se trata de una delegación parcial de la soberanía del Estado, que controla su recto ejercicio. Así, entre otros muchos procedimientos relativos a derechos reales, obligaciones, herencia, o derecho marítimo, cuya competencia se podría atribuir al Notariado, cabría señalar la inmatriculación mediante acta de notoriedad, la supresión de la intervención judicial homologadora de la decisión del Notario, en los supuestos de actas notariales de notoriedad para reanudar el tracto sucesivo o registrar los excesos de cabida, por suponer

${ }^{5}$ Vid en este sentido Rodríguez Adrados, Naturaleza jurídica del documento auténtico notarial, RDN, XLI-XLII, jul-dcb. 1963, pp 71-183; Id., Formación del instrumento público, validez, eficacia y libre circulación del negocio jurídico así documentado, incluso en las relaciones de Derecho Internacional Privado, RDN, XCVII-XCVIII, jul-dcb 1977, pp. 109-38; Id., La persistencia histórica de la oralidad en la escritura pública, Madrid, 1996, pp. 177 ss. 
una desnaturalización de la actividad notarial y una inapropiada desconfianza de su actuación, el reconocimiento de la intervención notarial en los casos de declaración de herederos a favor de parientes colaterales, la consignación de deudas dinerarias, las subastas voluntarias, la protesta de averías o el inventario de bienes.

No voy a entrar tampoco en este estudio, en el examen detallado de los procedimientos que, a mi juicio, especialmente en el campo del derecho de cosas y en el del tráfico mercantil de sociedades, cabría atribuir en esta materia, al otro relevante Cuerpo de Profesionales del Derecho, el de los Registradores de la Propiedad y Mercantiles, que en cuanto órganos de las Administración, que ejercen una potestad pública, a través del procedimiento registral, podrían asumir todos aquellos procedimientos que incardinados de manera especial, aunque no exclusiva, en el marco de los derechos reales, como la anotación preventiva del crédito refraccionario, o la rectificación de errores en los Asientos del Registro de la Propiedad y en el ámbito del derecho societario, como la convocatoria de juntas generales de sociedades anónimas, de responsabilidad limitada, o asambleas generales de cooperativas en determinados supuestos, o el nombramiento de interventores, liquidadores o auditores en situaciones concretas, tengan clara vocación registral.

Baste decir que, tanto en materia civil como en mercantil determinados procedimientos que se desjudicialicen pueden ser atribuidos con idéntica eficacia tanto a Notarios como a Registradores, que en los supuestos desjudicializados debe suprimirse toda huella procesal y de manifestación de imperio, y que es en sede de disposiciones finales de la futura Ley Jurisdicción Voluntaria, donde deben incluirse los supuestos que salen de la órbita judicial y en sede de la legislación hipotecaria, notarial y registral, donde debe residenciarse la regulación correspondiente.

Cabe afirmar, en definitiva, en relación con este punto, que el reconocimiento de potestad decisoria a los Secretarios Judiciales en el ámbito de la JV, como reconocidos expertos en derecho procesal, y a su configuración como Cuerpo superior jurídico y único, de carácter nacional, al Servicio de la Administración de Justicia, y la amplia desjudicialización de competencias y su atribución a Notarios y Registradores, como profesionales de acreditada solvencia jurídica y titulares de un servicio público que ejercen por delegación del Estado, supone a una racionalización del sistema, una descarga de trabajo para los Jueces y una lógica ratificación de confianza en la idoneidad de estos operadores jurídicos en el desempeño de esta función, así como en la madurez de la sociedad civil. 


\section{ALGUNAS VICISITUDES DE LA JURISDICCIÓN VOLUNTARIA A PARTIR DE LA RETIRADA DEL PROYECTO DE LEY SOBRE LA MATERIA EL 24 DE OCTUBRE DE 2007}

En el Proyecto de Ley de reforma de las leyes procesales para la implantación de la Oficina de 12 de diciembre de 2008 y, con posterioridad en la Ley, se optó por anticipar, de forma un tanto sorprendente, una nueva regulación de la conciliación, con atribución de la competencia al Secretario Judicial, sin tener en cuenta que en la Disposición Derogatoria única de la LEC del 2000, se establecía que la regulación de la conciliación conservaba su vigencia hasta la entrada en vigor de la futura Ley de Jurisdicción Voluntaria, que hubiera sido su sede natural. No resulta tampoco razonable que no se haga mención a las competencias de los Secretarios en materia de Jurisdicción Voluntaria, si bien se había anunciado por el Ministro de Justicia Fernández Bermejo, en sus comparecencias en el año 2008, ante las Comisiones de Justicia del Congreso de los Diputados y del Senado, la presentación en el año 2009 de un Proyecto de Ley sobre la materia, bajo la poco afortunada denominación de Procedimientos sin Contienda. El ministro Francisco Caamaño, en su comparecencia del pasado día 26 de marzo, respecto de la cual recordó que ya se pronunció en 1931 el entonces ministro de justicia Fernando de los Ríos, pero sorprendentemente no anunció un proyecto de ley en esta materia, pendiente de reforma desde el año 2001, conforme al mandato legal contenido en la D.F. 18 de la LEC, salvo la referencia a promover mecanismos de conciliación y mediación

En su comparecencia ante la Comisión de Justicia del Congreso de los Diputados el 26 de marzo de 2008, el Ministro de Justicia, Francisco Caamaño, se refirió a la necesidad de descargar a los juzgados de tareas no jurisdiccionales, y aludió en esta línea a la Jurisdicción Voluntaria, en concreto a la conciliación y a la mediación, si bien obvió el compromiso, en cumplimiento del mandato legislativo pendiente, de enviar a las Cortes un Proyecto de Ley, con carácter global, de Jurisdiccción Voluntaria, como se prevé en la Disposición Final 18 de la LEC. Las palabras, al respecto, del titular de la cartera de Justicia fueron las siguientes: «En este bloque de medidas para mejorar la calidad de nuestra justicia vamos a trabajar, también, en la búsqueda de fórmulas que contribuyan a reducir el número de litigios y la consiguiente carga de trabajo que soportan nuestros juzgados y tribunales.

Si volvemos la mirada atrás y repasamos los programas de acción que desde el Ministerio de Justicia se proponían hace ya más de se- 
tenta y cinco años, comprobaremos que ciertas cosas siguen en la agenda de lo querido pero no logrado. Fernando de Los Ríos allá por 1931 se lamentaba, como ministro de Justicia, de la carga de tareas que correspondían al juez más allá del núcleo de su función jurisdiccional por lo que se proponía, según sus palabras, «descargar a los Juzgados de lo que no tiene substantividad jurídica en un sentido ideológico ni en un sentido técnico», y citaba entre otras tareas las relativas a la jurisdicción voluntaria.

Aquella necesidad sentida entonces sigue vigente hoy. Hay que trabajar para evitar que se judicialicen conflictos que pueden encontrar una solución menos costosa fuera del sistema. Con ese fin vamos a promover la regulación de mecanismos de mediación y conciliación mediante los que se puedan resolver controversias con el consiguiente ahorro de costes para la Administración de justicia en términos de carga de trabajo y congestión. En este sentido mi Departamento cumplirá el mandato establecido por las Cortes Generales mediante la Ley 15/2005, de 8 de julio, y remitirá a esta Cámara un proyecto de ley de mediación que incorpore la normativa de la Unión Europea sobre la materia».

En marzo de 2011, el Real Patronato sobre Discapacidad elaboró una propuesta articulada en la que se contempla la modificación de los actuales artículos 199 a 201, correspondientes al Título IX, De la incapacitación, del Libro I del Código Civil, así como de los artículos 756 a 763, correspondientes al Capítulo II, De los procesos sobre la capacidad de las personas, del Título I, Libro IV, de la Ley de Enjuiciamiento Civil 1/ 2000. En la propuesta de revisión de los artículos correspondientes a la reforma de la LEC del año 2000, se establece que «la tramitación judicial relativa a la determinación o provisión de apoyos se realizará en el marco de un procedimiento de jurisdicción voluntaria específico, que se transformará en contencioso, en la modalidad de juicio verbal, si se formulase oposición por la persona con discapacidad o por persona o entidad legitimada», lo que, a mi juicio, debería haberse reflejado, por su razonabilidad, en el Borrador de Anteproyecto de Ley en materia de modificación judicial de la capacidad hecho público por el Ministerio de Justicia en la misma fecha de marzo de 2011.

\section{A MODO DE CONCLUSIÓN}

La seriedad con que, sin duda, se acometió el estudio de la JV, manifestada en la constitución de una Ponencia en el seno de la Co- 
misión General de Codificación, que elaboró un valioso texto prelegislativo entre los años 2002 a 2005, que sirvió de base al Proyecto del Gobierno , la comparecencia, en trámite de asesoramiento del Congreso de los Diputados, de 14 expertos sobre la materia y las 562 enmiendas presentadas por todos los grupos parlamentarios, así como en alto nivel técnico del texto legal aprobado en sede parlamentaria -la aprobación en el Congreso de enmiendas contradictorias se reducía a tan sólo dos artículos en materia de asistencia técnica y recursos- se vio frustrada, sin embargo, a mi juicio, por:

a) El cambió de concepción, respecto de lo previsto en el texto de la Ponencia, que supuso la inclusión en el Proyecto de una artificiosa equiparación entre procedimientos de diferente naturaleza, como son el judicial y el administrativo notarial y registral, lo que se materializó en la supresión de la contradicción, de los recursos y de la asistencia técnica y la representación procesal, en los procedimientos judiciales.

b) La oposición de algunos de los operadores jurídicos afectados, de forma singular, Secretarios Judiciales y Abogados, ante la desacertada previsión que implicaba un estéril reduccionismo de la JV al ámbito negocial y administrativo, debido a la supresión de las connotaciones jurisdiccionales del procedimiento judicial.

c) La articulación de un procedimiento judicial general unitario y garantista, en contraposición a la vigente previsión legal, que adolecía de esta nota caracterizadora, y su aplicación tan sólo a menores e incapaces, con el riesgo de ineficacia del procedimiento sustanciado ante los Secretarios Judiciales, y de frustración de estos operadores jurídicos, que se verían obligados a tramitar tan sólo los supuestos de ausencia de conflictividad, y a archivar el expediente en los restantes, obligando a los interesados a acudir a un juicio ordinario.

d) La polémica -surgida, a mi juicio, por una deficiente redacción legal- en torno a la consideración de no que parece la Ley de JV una ley adecuada para cambiar el actual modelo de seguridad jurídica preventiva y de fe pública, cuya probada eficacia y prestigio entre los justiciables y los operadores jurídicos, está fuera de toda duda razonable.

e) La inapropiada referencia a la naturaleza jurídica de la JV judicial en sede de Exposición de Motivos. El carácter controvertido de la cuestión en la doctrina española y europea, unido a la, a mi juicio, cuestionable ausencia de reserva jurisdiccional 
en los supuestos de atribución de competencias a los Jueces, hacen aconsejable o bien incardinar la materia en los apartados 3 y 4 del art. $117 \mathrm{CE}$, o bien incluso, lo que sería más prudente, no abordar la cuestión de la naturaleza de la JV en el texto legal.

Es hora ya de que la jurisdicción voluntaria deje de ser un campo de experimentación del legislador. Hay que elaborar una ley lo más completa posible que, escrita con buena técnica jurídica, conforme a las exigencias de la dogmática del derecho procesal:

a) articule un procedimiento general con todas las garantías inherentes a cualquier actuación judicial, entre las que cabe destacar, que la oposición no impida la continuación en la tramitación del expediente, salvo que la ley disponga lo contrario ,la posibilidad de recurrir en apelación el auto definitivo del Juez o en revisión el decreto del Secretario Judicial y el mantenimiento, salvo las excepciones previstas en la Ley, del carácter preceptivo de la asistencia técnica de abogado y la representación del procurador, junto con la previsión del beneficio de justicia gratuita, frente a la actual identificación de la institución con supresión o disminución de garantías, plazos o formalidades, en detrimento de la tutela judicial efectiva,

b) suprima los procedimientos obsoletos, reforme los todavía útiles, y traslade e incorpore de otros textos legales los que tienen naturaleza voluntaria,

c) desjudicialice competencias, en aras de la racionalización del sistema, y las atribuya a otros profesionales del derecho, Notarios y Registradores, de forma especial, las que razonablemente les correspondan por su propia naturaleza,

d) redistribuya competencias en el seno del órgano judicial entre Jueces y Secretarios Judiciales, y

e) reconozca al justiciable la posibilidad de optar, en determinados procedimientos respecto de los que no exista reserva judicial, entre acudir a un Secretario Judicial o a un operador jurídico extrajudicial, Notario o Registrador de la Propiedad o Mercantil, lo que constituye una manifestación de confianza en la madurez de la sociedad civil.

Estamos pues ante la necesidad de atender a una urgente necesidad social y de modernizar la Justicia en esta materia, caracterizada por la estrecha conexión con la vida diaria de los ciudadanos y por la relevante trascendencia práctica de muchas de sus manifestaciones, y 
de hacerlo con voluntad de permanencia en el tiempo, con el mayor consenso político posible, en una esfera del Ordenamiento de marcado carácter técnico-jurídico, en el que el debate no debe ser ideológico, sino en todo caso de concepción o filosofía de la jurisdicción voluntaria. Se trata, en definitiva, de dar respuesta, también en esta parcela del Ordenamiento Jurídico, al desafío de una Justicia más moderna, racional y eficaz ${ }^{6}$.

${ }^{6}$ Vid., en este sentido, en Fernández de Buján, Esperando a la Jurisdicción Voluntaria, Registradores, n. 42, enero-febrero 2008, pp.49 